\title{
Interactive comment on "Dynamic response of an Arctic epishelf lake to seasonal and long-term forcing: implications for ice shelf thickness" by Andrew K. Hamilton et al.
}

\section{Anonymous Referee \#1}

Received and published: 21 April 2017

Hamilton et al. present an extensive new dataset of hydrographic data from Milne Fiord epishelf lakes (MEL) in the Canadian Arctic combining both archive and extensive new CTD data. This is combined with ADCP, tidal height, mooring and AWS data to better understand the relationship between the depth of halocline and ice shelf thickness. Previous studies in the Arctic and Antarctic have used the depth of the halocline to infer long-term changes in ice shelf thickness. Whilst this simplistic model has been shown to hold true for some system, the overall complexity of this relationship has not been fully explored until now. I thoroughly enjoyed reading this paper - it is exceptionally thorough in its attempt to try and disentangle the various factors that control the depth of the halocline, involving the complex interaction of inflow and outflow of glacier melt,

Printer-friendly version

Discussion paper 
lake area and depth. Whilst it is often difficult to combine legacy data - both in terms of comparing data from different instrument as well as highly pronounced seasonality - the authors have done all they can to ensure that the patterns they observe are robust. More generally the paper is very well written and the authors explore each of the factors that can influence lake depth/depth of the halocline methodically. Other than a few queries/comments below I don't have much to add and commend the authors on such a thorough job! Page 3, figure caption. 'will not penetrate to the freshwater layer because the vertical ascent of the buoyant plume.' Yes, but not always the case especially if the Page 5, Figure 2. I'd include 'CTD locations' at top of white inset panel showing colour coded sites. Otherwise it's not immediately clear what they are. Page 6, Figure 3. Is this the only ice thickness data? A really nice thing to do in the future would be to measure ice shelf thinning/ice thickness and compare this with your detailed (and presumably ongoing?) hydrographic data. The ApRES system developed by the British Antarctic Survey/UCL would be ideal for this (Nicholls et al., A ground-based radar for measuring vertical strain rates and time-varying basal melt rates in ice sheets and shelves. Journal of Glaciology 61, 1079-1087). Also, label E-W fracture referred to on page 11, line 27. Page 6, section 2.2. Hydrography. Did you measure d180 of the lake water? I'm curious as to whether this would help refine your interpretation of the 2012 mixing event. As you say it is possible that this reflects a number of factors, although injection of a lot of glacier melt (possibly at depth) would be an interesting think to try and tease out. Page 11, section 3.3. Spatial extent. Is there any spatial bias in the seasonal changes observed between 2012 and 2013 plotted in Figure 5? If this is related to melt then spatial variability could be important? Page 22, line 19: Typo?! Likely enters the fiord at across the grounding line (remove 'at'?).

Interactive comment on The Cryosphere Discuss., doi:10.5194/tc-2017-19, 2017.

Printer-friendly version

Discussion paper 